Estudo do poder germinativo da semente de manga

\title{
SALIM SIMAO
}

E. S. A. "Luiz de Queiroz" 


\section{1 - INTRODUÇÃO}

Os porta-enxertos necessários a propagação da mangueira são obtidos a partir da sementes. Uma das maiores barreiras que se interpõe a produção de mudas no momento liga-se a rapida perda do seu poder germinativo.

$O$ crescente interêsse pelo plantio dessa excelente Anacardiaceae e a formação de novos pomares, evidência a importância que, na época atual, desempenha o conhecimento da duração e dos meios de conservar o poder germinativo das sementes de Manga.

Observações por nós feitas e citações de outros autores como LINCH \& MUSTARD (1955) e RUEHLE \& LEDIN (1955) confirmam esta assertiva, de que as sementes perdem sua vitalidade dentro de 4 semanas.

Com finalidade de investigar as causas que limitam o prazo de utilização das sementes, iniciamos a presente investigação.

\section{2 - MATERIAL E MÉTODO}

O ensaio teve lugar no (laboratório) da Secção Técnica de Horticultura da Escola Superior de Agricultura "Luiz de Queiroz".

Colheram-se 280 frutos de cada uma das 6 variedades estudadas: Bourbon, Brasil, Comum, Itamaracá, Non Plus Ultra e Oliveira Neto. A colheita foi feita em $15 / 12 / 58$ e o tratamento iniciado em $23 / 12 / 58$, quando os frutos estavam todos amadurecidos.

Foram feitos 7 tratamentos cada um com 40 sementes. Metade das sementes de cada tratamento foram mantidas em duas diferentes condições de conservação; um lote deixado a temperatura ambiente entre $20^{\circ} \mathrm{C}$ e $27^{\circ} \mathrm{C}$ e com umidade relativa entre 60 a $96 \%$ e outro levado a câmara frigorifica com temperatura ao redor de $5^{\circ} \mathrm{C}$ e umidade entre $85 \%$ e $92 \%$.

Os tratamentos foram assim executados:

1 - Sementes mantidas dentro dos frutos (frutos).

2 - Sementes retiradas dos frutos Caroço.

3 - Sementes retiradas dos frutos e descascada (Amendoa).

4 - Sementes retiradas dos frutos (Caroço) e tratadas com Zineb (Dithane) Z-78. 
5 - Sementes retiradas dos frutos (Caroço) cortados lateralmente e tratadas com Zineb.

6 - Amendoas tratadas com Zineb.

7 - Caroço estratificado em areia.

As observações eram efetuadas a intervalos de 5 dias, examinando-se 0 estado geral de 5 sementes em cada uma delas.

A perda de vitalidade das amendoas era determinada pelas alterações morfológicas e fisiológicas, tais como: enrugamento, endurecimento, transformação na côr e ataque de fungos.

$\mathrm{E}$ cada exame os caroços eram cortados e as sementes retiradas para anotações. As sementes de tôdas as variedades mantidas a temperatura ambiente, foram examinadas por etapas; as deixadas dentro dos frutos, só foram observadas após o desaparecimento da polpa envolvente, o que se deu entre 30 a 40 após o início do ensaio, e as deixadas com o caroço foram submetidas ao primeiro exame, 10 dias após a perda do poder germinativo das amendoas.

As sementes de todos os tratamentos conservados na câmara frigorifica, foram examinados a partir do $5 .^{\circ}$ dia do início dos experimentos, com baśe nas observações diárias, que indicavam o rapido decréscimo de atividade.

\section{3 - RESULTADOS}

Os resultados das observações sôbre a vitalidade das sementes são apresentados no quadro I.

O número de dias, representa o tempo médio de durabilidade quando ainda restavam de 15 a $25 \%$ de sementes viáveis, porcentagem esta considerada baixa para um aproveitamento por tempo mais prolongado.

Pelo exame das sementes mantidas a temperatura ambiente notou-se que as amendoas (tratamentos 3 e 6) não apresentavam mais condições de viabilidade em 2/1/59.

Em 12/1/59, as primeiras sementes de tôdas as variedades e dos tratamentos $2 ; 4,5$ foram cortadas e examinadas e encontravam-se em perfeitas condições de viabilidade. Em $17 / 1 / 59$, de cada 5 sementes examinadas, de 1 a 3 mostravam sinais evidentes de desintegração e em 22/1/59 tôdas as sementes restantes de cada variedade foram cortadas e os exames revelaram que apenas de 15 a $25 \%$ delas, ainda apresen- 


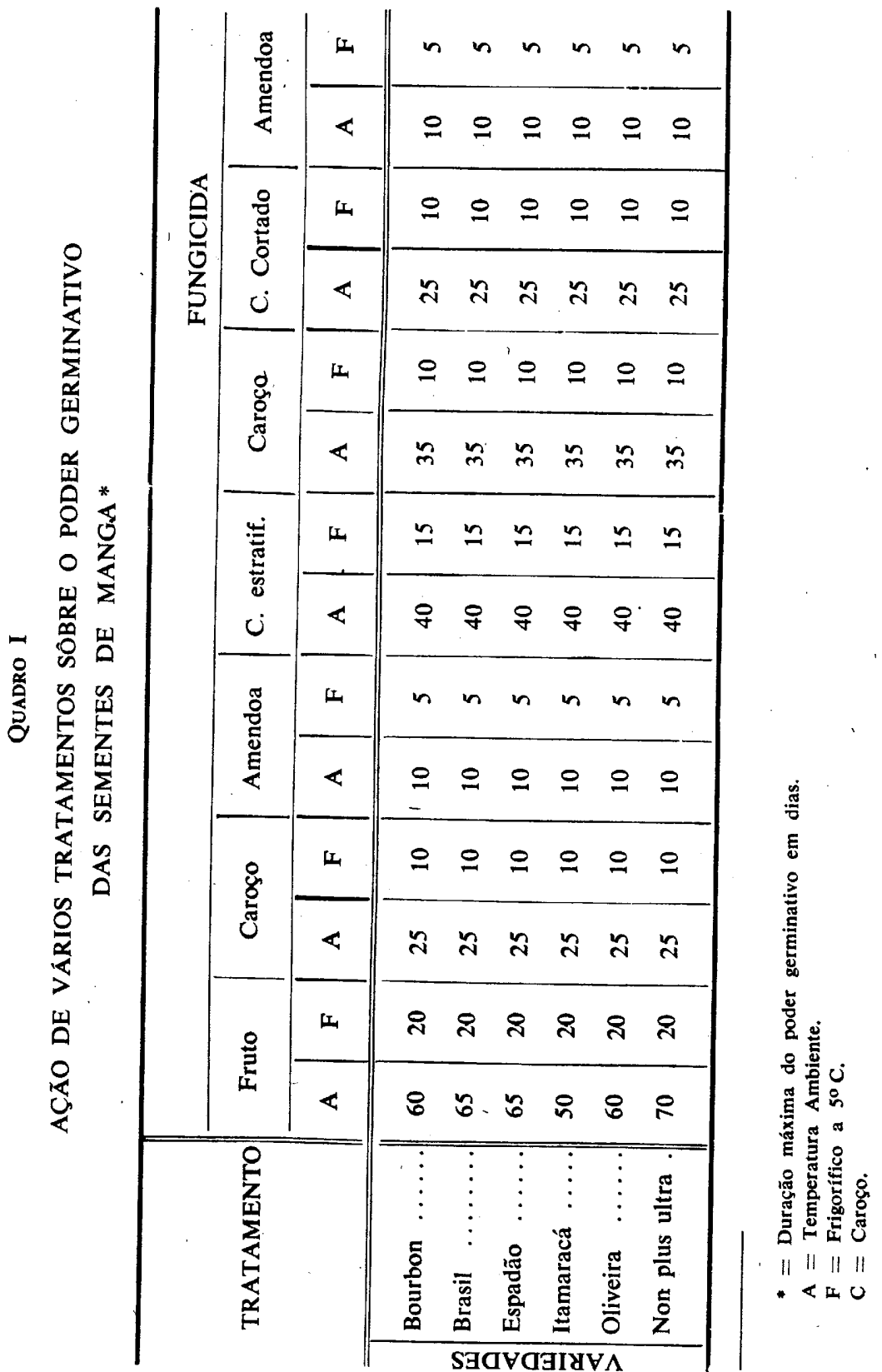


tavam certa viabilidade, as demais tinham perdido completamente o poder germinativo.

As do tratamento (5) cortada lateralmente ao atingirem o 25.0 dia mostravam-se em condições inferiores a do tratamento (2) porém sem nenhum sinal de ataque de fungo. Algumas delas, mostravam metade das amendoas já endurecidas $\mathrm{e}$ as partes restantes ainda com vitalidade. Ao atingirem 30 dias estavam quase tôdas inutilizadas enrugadas e secas. As sementes do tratamento 4 , foram as que melhor comportamento tiveram. De 30 a 35 dias de armazenamento mais de $25 \%$ delas eram viaveis e sem sinal de ataque por fungos.

As sementes extratificadas em areia, tratamento 7, apresentavam-se em bom estado de sanidade e turgescência até os 40 dias, já em 6 de fevereiro, as sementes de tôdas as variedades não excediam a $40 \%$ de viabilidade, sendo que a variadade Bourbon e Itamaracá mostravam ser as mais prejudicadas, com apenas $20 \%$ delas em condições mais ou menos vaiaveis.

As sementes mantidas nos frutos (tratamento 1) foram de todas as 'que exibiam um poder germinativo mais prolongado. Depois de 50 dias, excessão a variedade Itamaraca, mostravam-se em perfeitas condições. Dos 60 dias em diante o decrescimo da vitalidade das sementes das 5 variedades restantes era patente; e a medida que elas secavam, ataque de fungo recobria externamente as amendoas.

Pelas observações das sementes mantidas em câmara frigorifica, a temperatura de $5^{\circ} \mathrm{C}$ e umidade relativa entre $85 \%$ e $92 \%$, nota-se que em todos os tratamentos a duração do poder germinativo foi peqùena, de 5 dias para as amendoas, 10 dias para as sementes mantidas dentro do caroço, 15 dias em areia e 20 dias dentro dos frutos. Os cortes das sementes mostravam enegrecimento interno, e elas desfaziam-se facilmente a pressão dos dedos.

\section{4 - DISCUSSÃO}

Examinando-se as sementes deixadas a temperautra ambiente, nota-se que aquelas que permaneceram dentro dos frutos, tiveram seu poder germinativo prolongado em relação aos demais tratamentos.

Isto se deve possívelmente ao ambiente mais favoravel de unidade e temperatura. A umidade oferecida pelo fruto diminui lentamente a medida que a polpa desaparece. A temperatura da polpa junto ao caroço é menos variável que a do am- 
biente e as sementes conservadas dentro dos frutos recebem uma proteção natural por 30 a 50 dias, período êste, de duração da polpa. No fim resta apenas parte de casca endurecida e encrustada sôbre o caroço. O caroço ao termino do desaparecimento da polpa ainda se mantém entumecido, firme e pesado. Após o desaparecimento da polpa, é que se inicia própriamente a perda de vitalidade do caroço. Este torna-se mais leve, a amendoa se desprende e começa a murchar. Os frutos deixados amontoados exalam um cheiro algo desagradavel de fermentação.

A casca do fruto enegrece e assim se mantém até o final. A diferença de duração do poder germinativo, encontrada nas sementes mantidas dentro dos frutos deve ser levada em conta das diferenças de peso dos frutos, do que a vitalidade das sementes de cada variedade. Os frutos mais pesados possuem relativamente mais polpa. Essa deve ser uma das causas da mais rápida perda de vitalidade da semente da variedade Itamaracá e da maior duração da Non Plus Ultra: As variedades Espadinha e Brasil, embora considerados frutos de tamanho médio, semelhante em peso a Oliveira Neto e Bourbon tiveram o poder germinativo de suas sementes prolongado por mais alguns dias, em função queremos crer da presença de fibra de que elas são possuidas.

A polpa dos demais frutos é destituida desses elementos ou as possuem em muito menor proporção.

No quadro II apresentamos pêso médio dos frutos: polpa e semente.

QUÁ́ro II

PESO MÉdIO DE 10 FRUTOS EM GRAMAS

\begin{tabular}{l|l|l|l}
\hline & Frutos & Polpa & Caroço \\
\hline \hline Non Plus Ultra $\ldots \ldots \ldots$ & 575,0 & 522,9 & 521 \\
Bourbon $\ldots \ldots \ldots \ldots \ldots \ldots$ & 300,0 & 260,0 & 40,0 \\
Brasil $\ldots \ldots \ldots \ldots \ldots \ldots \ldots$ & 283,5 & 249,5, & 34,0 \\
Oliveira $\ldots \ldots \ldots \ldots \ldots \ldots$ & 279,5 & 243,5 & 36,0 \\
Comum $\ldots \ldots \ldots \ldots \ldots \ldots$ & 275,0 & 232,0 & 43,0 \\
Itamaracá $\ldots \ldots \ldots \ldots \ldots \ldots$ & 180,0 & 158,5 & 21,5 \\
\hline
\end{tabular}

Nota-se que a diferença do peso do fruto, polpa e do caroço é bem distinta entre Non Plus Ultra e Itamaracá, havendo 
entre as demais um relativo equilibrio, sendo que a Non Plus Ultra tem uma quantidade em peso de polpa quase o dobro das demais e 3 vêzes superior ao da Itamaracá.

Observando-se o poder germinativo das sementes mantidas dentro do caroço, nota-se que tôdas comportaram se de modo semelhante. $O$ poder germinativo decresceu rapidamente, o que podia ser constatado pelo escurecimento das amendoas, de côr normalmente creme, passava a pardacenta. As sementes contraiam-se e tornavam-se rijas e mostravam-se soltas dentro deles. Deve ter contribuido para esta rápida desidratação a temperatura ambiente, relativamente alta para a manutenção da viablididade da semente. Além disso algumas sementes mostravam-se enegrecidas, por ataque de fungos, 0 que em parte contribuiu para a perda rápida da sua viabilidade.

As amendoas, isto é, as sementes retiradas dos caroços, perderam praticamente a viabilidade em poucos dias o que era notado pelo amarelecimento das amendoas, além da redução de volume seguida de endurecimento.

As sementes tratadas com fungicida, principalmente as com caroço e cäroço cortado, mostraram um melhor comportamento. Isto se deve em parte a desinfecção, impedindo o aparecimento de fungos, que normalmente concorrem para o rapido desgaste das sementes e talvez de outro lado a maior umidade conferida pela imersão deles durante 15 minutos em solução com fungicida. O uso de sementes com caroço cortado, teve apenas por finalidade favorecer a penetração do fungicida. O seu comportamento foi inferior ao dos caroços inteiros, em virtude da incisão feita para permitir a penetração do fungidida, o qual favoreceu, assim, a mais rapida perda de umidade.

O tratamento fungicida das amêndoas não teve efeito algum no aumento da vitalidảde, pois esta desapareceu ao mesmo tempo que das sementes testemunhas.

As sementes mantidas extratificadas em areia, comportaram-se melhor. $O$ ambiente a elas fornecido impedia de um lado a perda de umidade e de outro mantinha uma temperatura mais constante. Não houve aí diferença sensivel sôbre o estado geral das sementes, tôdas elas mantiveram-se turgidas.

O exame dos 7 tratamentos mantidos a temperatura ambiente, leva-nos a supor que se conseguirmos armazenar as sementes em lugar arejado e mais fresco com temperatura menos variável, como ambiente de porão, a vitalidade das sementes de manga poderá ser prolongada. 
Examinando-se as sementes deixadas no frigorifico, nota-se que de um modo geral, perderam rapidamente a sua vitalidade. A causa principal da morte brusca dessas sementes foi devida ao efeito prejudicial da baixa temperatura a que foram submetidas.

As sementes, bem como os frutos mostravam sintomas característicos de queimaduras, as quais podiam facilmente ser notadas pelo enegrecimento das amendoas. $O$ caroço aparentemente não mostrava perda de turgescência, porem as amendoas a presentavam-se completamente farinhaceas, quebradiças, desfazendo-se com a mais leve pressão.

Se de um lado a temperatura elevada favorece a rapida perda de umidade, de outro, a temperatura muito baixa $\left(5^{\circ} \mathrm{C}\right)$ concorre para a queima e morte das sementes.

Estudos sobre a perda de pêso e de ambiete mais favoraveis, serão feitos com intuito de se elevar por mais tempo o poder germinativo das sementes dessa Anacardiaceae.

\section{5 - CONCLUSÖES}

Pelos exames feitos pôde-se tirar as seguintes conclusões:

1 - O poder germinativo das sementes de manga é de pequena duração, não ultrapassando a dois meses.

2 - O uso de fungicida melhorou as condições fito-sanitarias das sementes, aumentado sua viabilidade.

3 - A temperatura ao redor de $5^{\circ} \mathrm{C}$, causou queima nas sementes de todos os tratamentos.

4 - A extratificação em areia manteve por maior número de dias a vitalidade das sementes.

5 - A melhor conservação do poder germinativo foi obtido quando se deixou as sementes dentro dos frutos.

\section{6 - ABSTRACT}

\section{THE GERMINATING POWER OF SEEDS OF MANGO TREES.}

The author studied the storage of seeds of mango trees with the aim of Keeping higli its ability of germination.

Seven means of storage were tried, with two temperatures: environment temperature (22 to 27 degrees Centigrade) 
and cold store room (5 degrees centigrade). The methods of storage tried were:

1 - The frewit kept complete.

2 - Seeds taken within the stone.

3 - Seeds taken out of the stone.

4 - Stones heated with a Fungicida (Zineb).

5 - Stones cut laterally and heated with a fungicide (Zineb).

6 - Seeds (out of sones) heated with Zineb.

7 - Stones steatified with sand.

The best results were obtained for seeds kept within whole fruits, probably owing to protection provided by outer layers. The use of fungicide imposed the sanitary aspect of seeds and stones.

Storage in cold store room (5 degrees Centigrade) injured the seeds and stones in all cases.

Germinating power was kept high up to 70 days for complete fruits.

It seems that biggers fruits were more favorable to keep high the ability of theirs seeds to germinate.

\section{7 - BIBLIOGRAFIA}

LYNCH, S. J. \& M. J. MUSTARD, 1955 - Mangos in Florida. Departament of Agriculture, Tallahasse, Florida, Boletim n. ${ }^{\circ} 20-$ pp. 83.

RUEHLE, A. D. \& R. B. LEDIN, 1955 - Mango Growing in Florida, University, of Florida, Boletim 574, pp. 90. 
, 